\title{
CREEP DEFORMATION OF ALLOY 718
}

\author{
M.C. Chaturvedi \\ Department of Mechanical Engineering \\ University of Manitoba \\ Winnipeg, Canada, R3T 2N2 \\ Yafang Han \\ Institute of Aeronautical Materials \\ Beijing, People's Republic of China, 100095
}

\begin{abstract}
This paper deals with the steady state creep deformation of Alloy 718 which is precipitation strengthened by coherent $\gamma^{\prime \prime} \mathrm{DO}_{22}$ type and $\gamma^{\prime} \mathrm{L}_{2}$ type of precipitates. The results suggest that this material can deform by diffusional as well as by power law creep mechanisms depending upon the stress and temperature of deformation. Also, a transition region appears to exist between the regions of diffusional and power law creep. The grain size influences the steady state creep rate differently in the two regions and the effect of precipitate particle size on creep deformation has been analyzed.
\end{abstract}




\section{Introduction}

Most high temperature structures are designed to deform at a minimum creep rate in the steady state crcep stagc during their service. Therefore, it is of a great importance to predict the steady state creep rate and study the deformation behavior and mechanism of this creep stage for the materials used in the manufacturing of the high temperature structures. The steady state

creep rate $\varepsilon_{s}$ is dependent upon the applied stress, $\sigma_{a}$, temperature, $T$, as well as material parameters of grain size, dg, diffusivity, D, shear modulus, G, and Burger's vector, b, by the following equation (1)

$$
\dot{\varepsilon}_{\mathrm{s}}=A \frac{\mathrm{DGb}}{\mathrm{kT}}\left(\frac{\mathrm{b}}{\mathrm{dg}}\right) \mathrm{m}\left(\frac{\sigma_{\mathrm{a}}-\sigma_{\mathrm{o}}}{\mathrm{G}}\right) \mathrm{n}_{\mathrm{e}}
$$

where $\mathrm{k}$ is Boltzmann's constant, $\sigma_{\mathrm{o}}$ is the back stress opposing the dislocation motion during steady state creep, $\mathrm{A}, \mathrm{m}$ and $\mathrm{n}_{\mathrm{e}}$ are the constants which can be experimentally determined. Previous studies (2-9) have revealed that the deformation mechanisms that operate during high temperature creep of metals and alloys are characterized by the effective stress exponent $n_{e}$ in the creep rate equation (1), i.e., the value of $\mathrm{n}_{\mathrm{e}}$ has been observed to be equal to 1.0 for diffusional creep and to be between 3.0 and 6.0 for dislocation power law creep. In two phase alloys, the steady state creep rate is also affected by the second phase particle size $(3,9-11)$, i.e., the creep rate decreases with an increase in particle size until a minimum creep rate is reached and it then increases with a further increase in particle size of the second phase.

Since the commercial superalloy 718, which is strengthened by about $13 \mathrm{vol} \%$ of coherent ordered disc shaped BCT $\left(\mathrm{DO}_{22}\right) \gamma^{\prime \prime}$ phase and 4 vol \% of coherent ordered spherical $\mathrm{FCC}\left(\mathrm{L}_{2}\right) \gamma^{\prime}$ phase precipitates, has been widely used in the manufacture of equipment used at high temperatures, the effect of applied stress, operating temperature, grain size and precipitate particle size of $\gamma^{\prime \prime}$ and $\gamma^{\prime}$ phases on the creep deformation behaviour of Alloy 718 has been studied. An attempt has also been made to establish a steady state creep rate equation for this alloy in the temperature range of 853 to $943 \mathrm{~K}$ and the stress range of 620 to $840 \mathrm{MNm}^{-2}$.

\section{Materials and Experimental Techniques.}

The commercial nickel base superalloy 718 was provided by International Nickel Company of Canada. The chemical composition of the material was $0.03 \mathrm{C}-19.24 \mathrm{Fe}-18.24 \mathrm{Cr}-$ 0.52Al-0.9Ti-3.07Mo-4.94 ( $\left.\mathrm{N}_{\mathrm{b}}+\mathrm{T}_{\mathrm{a}}\right)-\mathrm{N}_{\mathrm{i}}$ Bal. The creep specimens, with a cross-section of 1.3 $\times 5.5 \mathrm{~mm}^{2}$ and a gauge length of $25.4 \mathrm{~mm}$, were machined from $1.3 \mathrm{~mm}$ thick strips cold rolled from the as-received $3.2 \mathrm{~mm}$ and $2.8 \mathrm{~mm}$ thick sheets. The creep specimens were annealed for $1 \mathrm{hr}$. at $1243,1273,1323$ and $1373 \mathrm{~K}$, respectively to obtain different grain sizes and water quenched, and then aged for $15 \mathrm{hrs}$ at $998 \mathrm{~K}$. The grain sizes, measured by the line-intercept method using a Leitz image plus analyser, were found to be $10,40,80,100 \mu \mathrm{m}$ for the above annealing temperatures. The particle sizes of $\gamma^{\prime \prime}$ and $\gamma^{\prime}$ precipitates were found to be $15.5 \mathrm{~nm}$ and $27.0 \mathrm{~nm}$ respectivcly. In order to study the particle size effect on creep deformation behaviour, the specimens were annealed at $1323 \mathrm{~K}$ for $1 \mathrm{hr}$, water quenched and then aged at $998 \mathrm{~K}$ for various lengths of time from $1 \mathrm{hr}$. to $100 \mathrm{hrs}$ to obtain various particle sizes of $\gamma^{\prime \prime}$ and $\gamma^{\prime}$ phases.

The tensile creep tests were conducted in two T-48 Avery-Denison constant stress creep machines with an argon atmosphere protecting specimens from oxidation. The creep strain was monitored during the tests by measuring the displacement of an extensometer attached to the specimen grips using an LVDT connected to a strip chart recorder. The testing temperature was controlled to within $\pm 2 \mathrm{~K}$. The back stress was determined by the consecutive stress reduction 
method [4,5]. The experimental details of measuring back stress have been described elsewhere [13].

Transmission electron microscopy was used for examining the microstructures of the creep specimens, and the dark field technique of TEM was used to measure the second phase particle size. The thin foils for TEM were electropolished in a jet electropolishing bath of $15 \%$ perchloric acid and $85 \%$ methanol in the temperature range of 223 to $233 \mathrm{~K}$. The prepared thin foils were examined in a Philips 300 transmission electron microscope.

\section{$\underline{\text { Results and Discussion }}$}

\section{Effective Stress Exponents $n_{2}$ and Creep Mechanisms,}

As mentioned earlier, the creep deformation mechanisms during the steady state creep stage are characterized by the effective stress exponent $n_{e}$ in the creep rate equation (1). Therefore, a determination of the value of $n_{e}$ is essential to study the creep mechanisms. In order to determine the effective stress exponents $n_{\mathrm{e}}$ the creep rates $\varepsilon_{\mathrm{s}}$ and back stresses $\sigma_{0}$ were experimentally determined in the temperature range of $853-943 \mathrm{~K}$ in the stress range of $620-840$ $\mathrm{MN} \mathrm{m} \mathrm{m}^{-2}$ by using the specimens with grain sizes of $10,40,80$ and $100 \mu \mathrm{m}$. The results are shown in Table I.

Table I. Experimentally Determined Values of $\mathbf{n}_{\mathbf{e}}$ and $\sigma_{0}$ (Specimens Aged for 15 hrs at $998 \mathrm{~K}$ with $\mathrm{d} \gamma^{\prime \prime}=27.0 \mathrm{~nm}, \mathrm{~d} \gamma^{\prime}=15.5 \mathrm{~nm}$ )

\begin{tabular}{rcccc}
\hline $\begin{array}{c}\text { Grain Size } \\
(\mu \mathrm{m})\end{array}$ & $\begin{array}{c}\text { Testing Temp. } \\
(\mathrm{K})\end{array}$ & $\begin{array}{c}\text { Applied Stress, } \sigma_{\mathrm{a}} \\
\left(\mathrm{MN} / \mathrm{m}^{2}\right)\end{array}$ & $\begin{array}{c}\text { Back Stress, } \sigma_{\mathrm{o}} \\
\left(\mathrm{MN} / \mathrm{m}^{2}\right)\end{array}$ & $\mathrm{n}_{\mathrm{C}}$ \\
\hline 80 & 853 & $643,690,746$ & 617 & $1.2+0.2$ \\
\hline & & & \\
10 & 873 & 670,700 & 576 & $1.16 \pm 0.1$ \\
40 & 873 & 670,700 & 576 & $1.44 \pm 0.1$ \\
80 & 873 & $620,670,746$ & 576 & $1.40 \pm 0.1$ \\
100 & 873 & 670,700 & 576 & $1.37 \pm 0.1$ \\
\hline & & & & \\
10 & 898 & 650,690 & 540 & $1.34 \pm 0.2$ \\
40 & 898 & 650,690 & 540 & $1.60 \pm 0.2$ \\
& & & & $1.54 \pm 0.2$ \\
80 & 898 & $620,670,720$ & 540 & \\
100 & 898 & 650,690 & 540 & $2.3 \pm 0.3$ \\
& & & & $5.9 \pm 1.9$ \\
80 & 923 & $620,670,695$ & 510 & $5.1 \pm 1.5$ \\
80 & 943 & $620,670,695$ & $437,460,473$ & $5.9 \pm 0.6$ \\
80 & 873 & $765,815,840$ & $588,605,613$ & \\
80 & 898 & $765,815,840$ & $571,582,587$ & \\
& & & &
\end{tabular}


The values of the effective stress exponents, $n_{e}$, in the creep rate equation (1) were determined from the slopes of the plots of $\log \varepsilon_{\mathrm{s}}$ vs. $\log \left(\sigma_{\mathrm{a}}-\sigma_{\mathrm{o}}\right) / \mathrm{G}$. Figures 1 and 2 show these plots for determining the values of $n_{\mathrm{e}}$.

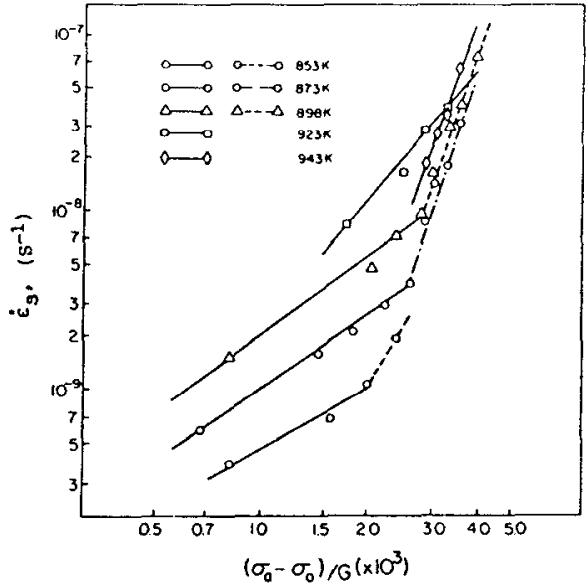

Fig. 1. Log-log plots for determining the values of $n_{e}$ for specimens with a grain size of $80 \mu \mathrm{m}$ tested in the temperature range of $853-943 \mathrm{~K}$ and in the stress range of $620-720 \mathrm{MN}$ $\mathrm{m}^{-2}(\longrightarrow)$ and $765-840 \mathrm{~K} \mathrm{MN} \mathrm{m}^{-2}$ $(---)$

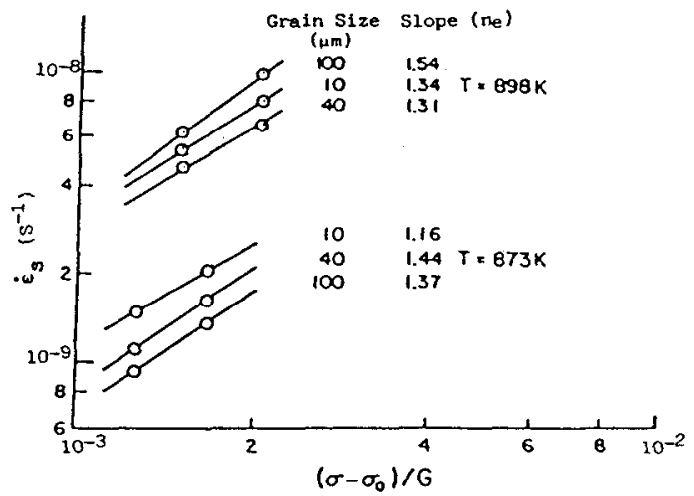

Fig. 2 Log-log plots for determining the values of $\mathrm{n}_{\mathrm{e}}$ for specimens with grain sizes of $10,40,100 \mu \mathrm{m}$ tested at $873 \mathrm{~K} /(670-700) \mathrm{MN} \mathrm{m}^{-2}(\mathrm{o})$, and $898 \mathrm{~K} /(650-690) \mathrm{MN} \mathrm{m}^{-2}(\odot)$

According to Lasalmonie and Strudel [1] and Sherby and Burke [2], when the stress exponent of the creep rate equation, $\mathrm{n}_{\mathfrak{e}}=1.0$, the creep deformation is controlled by diffusional creep and when $n_{e}=3.0-7.0$, the dislocation power law mechanism controls the creep deformation. The experimental results given in Table I show that the value of the effective stress exponent, $n_{e}$, increases as either the testing temperature or the applied stress increases. This suggests that the creep mechanism changes from diffusional or linear creep to dislocation power law creep as the temperature increases from 853 to $943 \mathrm{~K}$ in the applied stress range of $620-720 \mathrm{MN} \mathrm{m}^{-2}$, and as the applied stress, $\sigma_{\mathrm{a}}$, increases from $620-720 \mathrm{MN} \mathrm{m}^{-2}$ to $765-840$ $\mathrm{MN} \mathrm{m}^{-2}$ in the temperature range of $873-898 \mathrm{~K}$. This is also shown schematically in Fig. 3. The fact that the values of $n_{e}$ are slightly greater than one, as shown in Table $I$, even in the diffusional creep regions mentioned above may be attributed to the different deformation mechanisms during creep in two-phase alloys than in single phase alloys and pure metals, i.e., diffusional creep in two-phase alloys involves not only vacancy diffusion in the matrix and dislocation motion in the grain boundary region but also dislocation creation and motion within the grains [14]. The characteristics of diffusional creep in two-phase alloys have been also discussed in detail previously [14]. The theoretical model of diffusional creep in two phase alloys proposed by Harris [15] and Burton [16] predict that precipitate-free zones (PFZ) should be present around grain boundaries that are in tension when a creep test lasts for a sufficiently long time. Therefore, in order to confirm the diffusional creep, thin foil electron microscopy was used to observe the microstructures before and after creep tests. It was observed that the precipitate-free zones do exist in specimens with a grain size of $10 \mu \mathrm{m}$ creep deformed at $873 \mathrm{~K}$ under a stress of $700 \mathrm{MN} \mathrm{m}^{-2}$ for $1086 \mathrm{hrs}$ and at $690 \mathrm{MNm}^{-2}$ for $1500 \mathrm{hrs}$, where the value of $n_{e}$ is equal to $1.16 \pm 0.1$. However, no precipitate free zones were observed in the grip portions of the above creep deformed specimens and the specimens before creep tests. The PFZ were also not observed in specimens creep tested under conditions where creep was controlled by dislocation climb mechanism. 
The experimental results in Table I show that the value of effective stress exponent $n_{\mathrm{e}}$, changes continuously from 1.2 to 5.9 when the testing temperature changes from 853 to $943 \mathrm{~K}$ in the low stress range of $620-720 \mathrm{MN} \mathrm{m}^{-2}$. This suggests that there exists a transition creep region between diffusional or linear creep and homogeneous power law creep [14]. Diffusional fluw can be considered as grain boundary sliding with diffusional accomodation. During this process, incompatability generated by grain boundary sliding is removed at a steady rate by diffusion of atoms from sources on some grain boundaries to sinks on others. If the strain rate is increased sufficiently, diffusion can no longer accomodate the sliding and a non-uniform power law creep within grains, called "folds", appears. As the strain rate increases further, "folds" disappear, which leads to homogeneous power law creep. The region where diffusion can no longer accomodate the grain boundary sliding, and non-uniform power law creep appears, is designated as a "transition region" between diffusional and power law creep. In the "transition region" there exists a optimum grain size where a creep rate minimum is observed, as shown in Fig. 3. This aspect will be discussed later. From the results given in Table I, the average value of effective stress exponents, $n_{e}$, can be obtained, i.e., $n_{e}=1.35$ in the diffusional creep region, and $n_{e}=5.6$ in the dislocation power law creep regions.

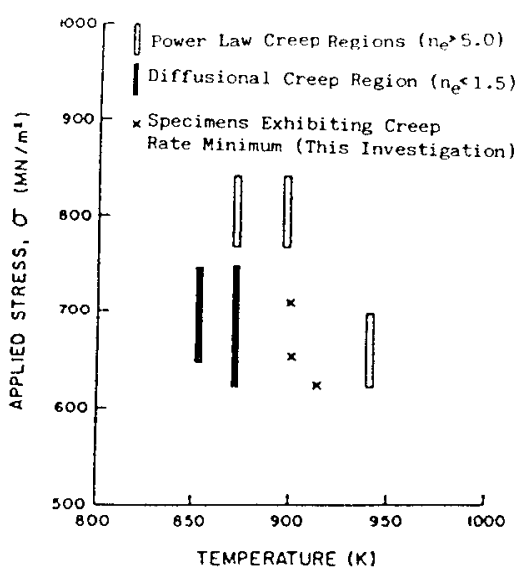

Fig. 3. Steady state creep region for Alloy 718

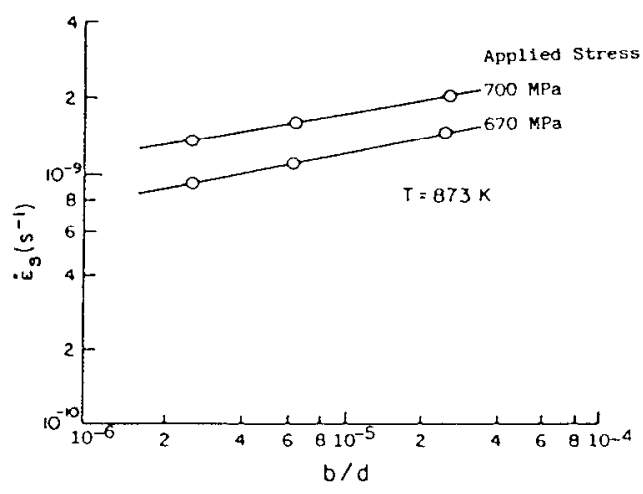

Fig. 4. Effect of grain size on diffusional creep rate

\section{Effect of Grain Sizc on Crecp Rate}

Since the diffusion process is generally involved during high temperature deformation of both diffusional creep and dislocation power law creep regions of two phase alloys, the grain size effect on creep rate [1] is expected to be as shown in equation (1).

In order to determine the value of grain size exponent, $m$, in equation (1) the steady state creep rates, $\dot{\varepsilon}_{\mathbf{s}}$, of the specimens with different grain sizes were measured in the temperature range of $873-923 \mathrm{~K}$ and in the stress range of $650-820 \mathrm{MN} \mathrm{m}^{-2}$, respectively. The results are shown in Table II. It is seen that in the diffusional creep region where $n_{\mathfrak{c}}=1.16-1.44$, i.e., $\sigma_{\mathrm{a}}$ $=670-700 \mathrm{MN} \mathrm{m}^{-2}$ at $873 \mathrm{~K}$, the creep rate, $\dot{\varepsilon}_{\mathrm{s}}$, decreases with increasing grain size, while in the transition region where $n_{e}=1.6-2.3$, there exists a minimum creep rate when the grain size is $40 \mu \mathrm{m}$. The plots of $\log \varepsilon_{\mathrm{s}}$ vs. $\log$ (b/d) for a testing temperature of $873 \mathrm{~K}$ and applied stresses of 670 and $700 \mathrm{MN} \mathrm{m}^{-2}$ are shown in Figure 4. The values of $\mathrm{m}$ calculated from the slopes of these plots are 0.20 and 0.18 for the applied stresses of 670 and $700 \mathrm{MN} \mathrm{m}^{-2}$, respectively, which gives an average value of $m=0.19$. This value is much smaller than the values of 2 predicted by the volume diffusion controlled creep model of Nabarro-Herring and 3 by the grain boundary diffusion controlled creep model of Coble for diffusional creep in single phase alloys and pure metals. This may be attributed to the different mechanisms of creep that 
operate in two phase and single phase alloys [14], and therefore a different grain size exponent value may be expected, i.e., the creep rate will be much less sensitive to the grain size in two phase alloys than in single phase alloys as the interfaces of matrix and second phase particles also act as the obstacles for diffusion process in two phase alloys.

Table II: Influence of Grain Size on the Steady State Creep Parameters.

\begin{tabular}{|c|c|c|c|c|c|c|c|}
\hline $\begin{array}{l}\text { Solution } \\
\text { Treatment } \\
\text { Temp. (K) }(1 \text { h.) }\end{array}$ & $\begin{array}{l}\text { Grain } \\
\text { Size } \\
(\mu \mathrm{m})\end{array}$ & $\begin{array}{l}\text { Testing } \\
\text { Temp. (K) }\end{array}$ & $\begin{array}{l}\text { Applied } \\
\text { Stress } \\
\left(\mathrm{MN} / \mathrm{m}^{2}\right)\end{array}$ & $\begin{array}{l}\text { Creep } \\
\text { Rate } \\
\dot{\varepsilon}_{\mathrm{s}}\left(10^{-9} \mathrm{~S}^{-1}\right)\end{array}$ & $\begin{array}{c}\mathrm{n}_{\mathrm{e}} \\
\text { From } \\
\text { EQ.(1) }\end{array}$ & $\mathrm{n}_{\mathrm{e}}^{*}$ & $\begin{array}{r}\sigma_{a}{ }^{*} \\
\left.\mathrm{~N} / \mathrm{m}^{2}\right)\end{array}$ \\
\hline $\begin{array}{l}1243 \\
1273 \\
1373\end{array}$ & $\begin{array}{r}10 \\
40 \\
100\end{array}$ & $\begin{array}{l}873 \\
873 \\
873\end{array}$ & $\begin{array}{l}670 \\
670 \\
670\end{array}$ & $\begin{array}{l}1.48 \\
1.10 \\
0.93\end{array}$ & $\begin{array}{l}1.16 \\
1.44 \\
1.37\end{array}$ & $1.3 \pm 0.1$ & $\begin{array}{l}576 \\
576 \\
576\end{array}$ \\
\hline $\begin{array}{l}1243 \\
1273 \\
1373\end{array}$ & $\begin{array}{r}10 \\
40 \\
100\end{array}$ & $\begin{array}{l}873 \\
873 \\
873\end{array}$ & $\begin{array}{l}700 \\
700 \\
700\end{array}$ & $\begin{array}{l}2.04 \\
1.64 \\
1.36\end{array}$ & $\begin{array}{l}1.16 \\
1.44 \\
1.37\end{array}$ & $1.4 \pm 0.1$ & $\begin{array}{l}576 \\
576 \\
576\end{array}$ \\
\hline $\begin{array}{l}1243 \\
1273 \\
1373\end{array}$ & $\begin{array}{r}10 \\
40 \\
100\end{array}$ & $\begin{array}{l}873 \\
873 \\
873\end{array}$ & $\begin{array}{l}820 \\
820 \\
820\end{array}$ & $\begin{array}{l}3.40 \\
7.39 \\
8.60\end{array}$ & & $5.1+1.5$ & $\begin{array}{l}605 \\
605 \\
605\end{array}$ \\
\hline $\begin{array}{l}1243 \\
1273 \\
1373\end{array}$ & $\begin{array}{r}10 \\
40 \\
100\end{array}$ & $\begin{array}{l}898 \\
898 \\
898\end{array}$ & $\begin{array}{l}650 \\
650 \\
650\end{array}$ & $\begin{array}{l}5.13 \\
4.60 \\
5.89\end{array}$ & $\begin{array}{l}1.34 \\
1.31 \\
1.54\end{array}$ & $1.6+0.2$ & $\begin{array}{l}540 \\
540 \\
540\end{array}$ \\
\hline $\begin{array}{l}1243 \\
1273 \\
1373\end{array}$ & $\begin{array}{r}10 \\
40 \\
100\end{array}$ & $\begin{array}{l}898 \\
898 \\
898\end{array}$ & $\begin{array}{l}690 \\
690 \\
690\end{array}$ & $\begin{array}{l}7.74 \\
6.83 \\
9.44\end{array}$ & $\begin{array}{l}1.34 \\
1.31 \\
1.54\end{array}$ & $1.6+0.2$ & $\begin{array}{l}540 \\
540 \\
540\end{array}$ \\
\hline $\begin{array}{l}1243 \\
1273 \\
1373\end{array}$ & $\begin{array}{r}10 \\
40 \\
100\end{array}$ & $\begin{array}{l}923 \\
923 \\
923\end{array}$ & $\begin{array}{l}650 \\
650 \\
650\end{array}$ & $\begin{array}{l}14.91 \\
13.58 \\
20.05\end{array}$ & & $2.3+0.3$ & $\begin{array}{l}510 \\
510 \\
510\end{array}$ \\
\hline
\end{tabular}

* Grain Size $=80 \mu \mathrm{m}$

In the dislocation power law creep region where $n_{e}=5.1$, i.e., $\sigma_{a}=820 \mathrm{MN} \mathrm{m}^{-2}$ at $873 \mathrm{~K}$, the steady state creep rate increases with increasing grain size. The $\log \varepsilon_{s}$ vs. $\log (\mathrm{b} / \mathrm{d})$ plot in this region is shown in Figure 5, and the calculated value of $m$ in equation (1) is -0.42 .

\section{Determination of Constant $A$ in the Creep Rate Equation}

To determine the material constant $A$ in the creep rate equation (1), the value of diffusivity, D, should be determined. Since $\mathrm{D}$ has the normal form of $\mathrm{D}=\mathrm{D}_{\mathrm{o}} \mathrm{e}-\mathrm{Q} / \mathrm{RT}$, where $\mathrm{Q}$ is activation energy during creep, the value of $\mathrm{D}$ can be determined by the determination of activation energy, Q, during creep. From equation (1), the slopes of the plots of $\ln \frac{\varepsilon_{\mathrm{s}} T}{\mathrm{G}}\left(\frac{\mathrm{G}}{\sigma_{\mathrm{a}}-\sigma_{\mathrm{o}}}\right)^{n_{\mathrm{e}}}$ vs. $1 / \mathrm{T}$ for constant grain size will yield values of $\mathrm{Q} / \mathrm{R}$ from which $\mathrm{Q}$ can be calculated. The plots for $n_{e}=1.35$ are shown in Fig. 6 .

The values of activation energies for the $10 \mu \mathrm{m}$ and $40 \mu \mathrm{m}$ grain size material were calculated to be the same, i.e., $Q=264 \mathrm{~kJ} / \mathrm{mol}$. If the data for $100 \mu \mathrm{m}$ grain size were included, 


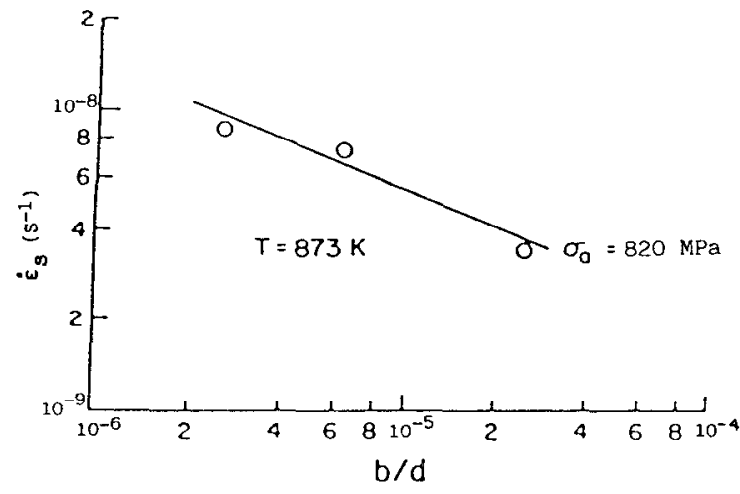

Fig. 5. Effect of grain size on power law creep rate

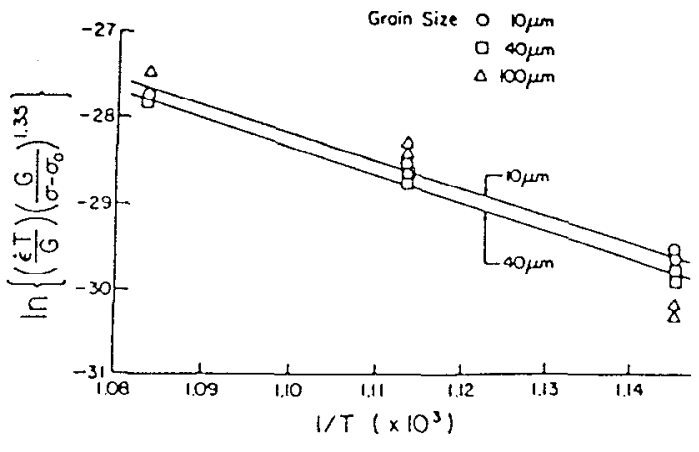

Fig. 6. Activation energy plots for $n_{e}=1.35$

the activation energy would be only slightly higher. The activation energy in the dislocation power law creep region where $n_{e}=5.5$ was found to be $285 \mathrm{~kJ} / \mathrm{mol}$. These two values are close to the lattice self diffusion activation energy for $\mathrm{Ni}, 280 \mathrm{~kJ} / \mathrm{mol}$. Therefore, it is reasonable to assume that the value of the coefficient of diffusion in Alloy 718 is similar to that for diffusion in nickel. By taking $\mathrm{D}=1.98 \times 10^{-4} \mathrm{e}-280,000 / \mathrm{RT} \mathrm{m}^{2} / \mathrm{S}$ the material constant, $\mathrm{A}$, in equation (1) can be determined, i.e., $A=1.6 \times 10^{-5}$ in diffusional creep region and $A=75$ in power law creep region. Therefore, the creep rate of Alloy 718 is given by:

$$
\dot{\varepsilon}_{\mathrm{s}}=1.6 \times 10^{-5} \frac{\mathrm{D}_{1} \mathrm{~Gb}}{\mathrm{KT}}\left(\frac{\mathrm{b}}{\mathrm{d}_{\mathrm{g}}}\right){ }^{0.19}\left(\frac{\sigma_{\mathrm{a}}-\sigma_{\mathrm{o}}}{\mathrm{G}}\right) 1.35
$$

for diffusional creep region and

$$
\dot{\varepsilon}_{\mathrm{s}}=75 \frac{\mathrm{D}_{1} \mathrm{~Gb}}{\mathrm{KT}}\left(\frac{\mathrm{b}}{\mathrm{d}_{\mathrm{g}}}\right)^{-0.42}\left(\frac{\sigma_{\mathrm{a}}-\sigma_{\mathrm{o}}}{\mathrm{G}}\right)^{5.6}
$$

for dislocation power law creep region.

However, in the transition region between diffusional creep and dislocation power law creep regions it is reasonable to assume that both processes contribute to the creep rate and the total creep rate in transition creep region may be written as:

$$
\begin{gathered}
\dot{\varepsilon}_{\mathrm{s}(\text { total })=} 1.6 \times 10^{-5} \mathrm{f}_{\mathrm{D}} \frac{\mathrm{D}_{1} \mathrm{~Gb}}{\mathrm{KT}}\left(\frac{\mathrm{b}}{\mathrm{d}_{\mathrm{g}}}\right){ }^{0.19}\left(\frac{\sigma_{\mathrm{a}}-\sigma_{\mathrm{o}}}{\mathrm{G}}\right)^{1.35+} \\
75\left(1-\mathrm{f}_{\mathrm{D}}\right) \frac{\mathrm{D}_{1} \mathrm{~Gb}}{\mathrm{KT}}\left(\frac{\mathrm{b}}{\mathrm{d}_{\mathrm{g}}}\right)^{-0.42}\left(\frac{\sigma_{\mathrm{a}}-\sigma_{\mathrm{o}}}{\mathrm{G}}\right)^{5.6}
\end{gathered}
$$

where $\mathrm{f}_{\mathrm{D}}$ is the fraction of diffusional creep. By taking $\partial \dot{\varepsilon}_{\mathrm{s}}$ (total) $/ \partial \mathrm{d}_{\mathrm{g}}=\mathrm{o}$ the optimum grain size for minimum creep rate can be obtained. For the creep test conditions of $690 \mathrm{MN} / \mathrm{m}^{2}$ at $898 \mathrm{~K}$ and $650 \mathrm{MN} / \mathrm{m}^{2}$ at $923 \mathrm{~K}$, where the effective stress is equal to 150 and $140 \mathrm{MN} / \mathrm{m}^{2}$, respectively, the values of optimum grain size were calculated to be $32 \mu \mathrm{m}$ and $47 \mu \mathrm{m}$, respectively, by assuming that $\mathrm{f}_{\mathrm{D}}=0.5$. These calculated optimum grain sizes are in good agreement with the experimentally observed values of $40 \mu \mathrm{m}$ indicated in Table I. 


\section{Effect of Particle Size on Steady State Creep Rate}

The effect of second phase particle size on the steady state creep rate, $\varepsilon_{\mathrm{s}}$, in two phase alloys has been investigated previously and several theoretical models have been proposed $[10,11,18$, 19]. To study the influence of the precipitate particle size on secondary creep rate in the present alloy the creep tests of the specimens aged at $998 \mathrm{~K}$ for various lengths of time were conducted at $873 \mathrm{~K}$ and at stresses of $670,695,720,765$ and $815 \mathrm{MN} \mathrm{m}^{-2}$, and the results are shown graphically in Figure 7. The values of exponent $\mathrm{p}$ in the equation of $\dot{\varepsilon}_{\mathrm{s}} \alpha \mathrm{d}_{\gamma^{{ }^{\mathrm{p}}}}$ for various stress levels are listed in Table III.

Table III: Experimentally Determined Exponent $p$ of Equation $\varepsilon_{s} \alpha d_{\gamma^{\prime \prime}}{ }^{p}$ for Specimens Tested at $873 \mathrm{~K}$

underaged condition $\left(\mathrm{d}_{\gamma^{\prime \prime}}<23 \mathrm{~nm}\right) \quad$ Overaged condition $\left(\mathrm{d} \gamma^{\prime \prime}>23 \mathrm{~nm}\right)$

\begin{tabular}{cccccccccccc}
$\left(\mathrm{MN} / \mathrm{m}^{2}\right)$ & 690 & 695 & 720 & 746 & 765 & 815 & 670 & 695 & 720 & 765 & 815 \\
\hline$p$ & -1.9 & -2.1 & -2.0 & -2.2 & -2.5 & -3.4 & 2.5 & 2.4 & 2.4 & 2.5 & 2.4 \\
\hline
\end{tabular}

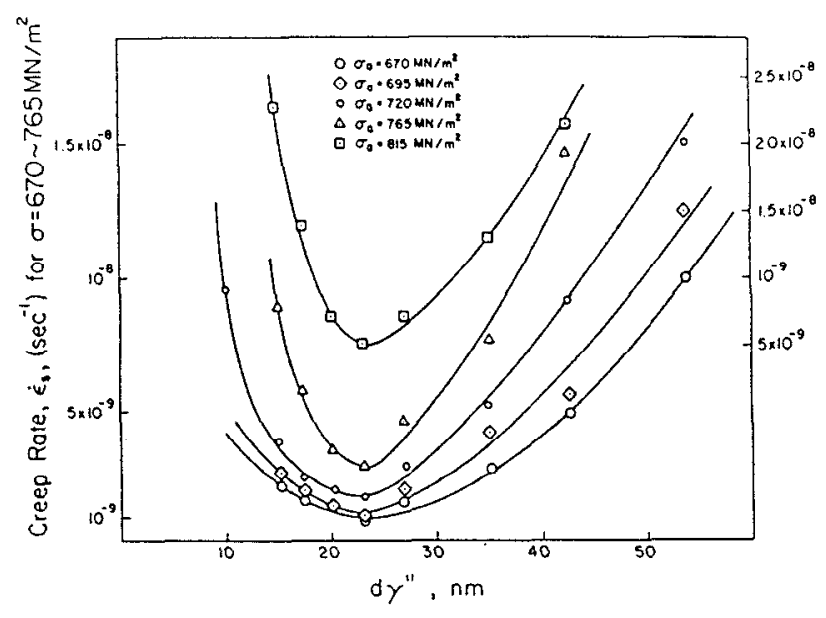

Fig. 7. Dependence of $\varepsilon_{s}$ on particle size, $\mathrm{d} \gamma^{\prime \prime}$, at various stress levels, the specimens were aged for various periods of time at $998 \mathrm{~K}$ and tested at $873 \mathrm{~K}$

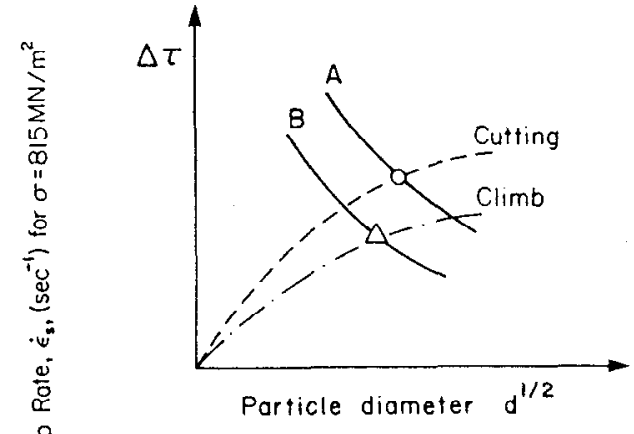

Fig. 8.

Schematic aging-hardening curves, illustrating the particle size of the optimum room temperature yield strength (o) and the particle size of the optimum high temperature creep resistance $(\Delta)$; curve $A$, bowing-out at room temperature; curve $\mathrm{B}$, bowingout at a high temperature 
These results show that at all the stress levels the steady state creep rate first decreases with increasing particle size until a critical particle size is reached. It then increases with further increase in particle size. The results of the underaged specimens seem to be in general agreement with the models proposed by Ansell and Weertman [10] and by Mclean [18], both of which suggests that $\dot{\varepsilon}_{\mathrm{s}} \propto \mathrm{d}^{-2}$. In the overaged condition, however, results seem to follow the models of Grant [11] and Mclean and Hale [19] who suggest that $\dot{\varepsilon}_{\mathrm{s}} \alpha \mathrm{d}^{2}$.

It is observed that the particle sizes of the specimens with an optimum creep resistance, where $\mathrm{d} \gamma^{\prime \prime}=23.2 \mathrm{~nm}, \mathrm{~d} \gamma^{\prime}=13.7 \mathrm{~nm}$ produced by ageing for 10 hours at $998 \mathrm{~K}$, are slightly smaller than those observed in specimens with a maximum room temperature yield strength, i.e., $\quad \mathrm{d} \gamma^{\prime \prime}=27.0 \mathrm{~nm}, \mathrm{~d} \gamma^{\prime}=15.5 \mathrm{~nm}$ in the specimen aged for 15 hours at $998 \mathrm{~K}$ [20]. This observation is similar to that observed in $\mathrm{Ni}-\mathrm{Cr}-\mathrm{Al}-\mathrm{Ti}$ alloys containing a $10-20 \%$ volume

fraction of $\gamma^{\prime}$ phase [21]. There are two possible explanations for this behaviour. Firstly, the deformation mechanism of high temperature creep is different than that of a room temperature tensile test. Authors' previous studies [14,20] on Alloy 718 revealed that, in the underaged condition, second phase particles are cut by moving dislocations during room temperature deformation [20], while in high temperature creep, dislocations are believed to climb over the particles [14]. It is also believed [22] that the applied stress required for dislocations to cut or shear particles is higher than that required to climb over the particles, as shown in Fig. 8. In the overaged condition, during both room temperature deformation and high temperature creep, dislocations bow out between the particles and leave dislocation loops around the particles, forming dislocation pile-ups $[14,20]$. However, in room temperature deformation, these dislocation pile-ups will result in higher values of stress opposing dislocation motion, while during high temperature creep the opposing stress due to pile-ups can be decreased by climb of the innermost loop and self-annihilation, permitting the next dislocation to bow out [10]. Therefore, the applied stress required for dislocations to bow out between the particles during room temperature deformation will be higher than that during high temperature creep. Furthermore, higher thermal energy is available during high temperature creep than during room temperature deformation. This should assist the bowing out of dislocations. It is known that the optimum particle size for room temperature yielding is obtained when the particle increases to a dimension where the applied shear stress required for dislocations to cut the particles is equal to that required for the dislocations to bow out between the particles [23]. Therefore, this particle size during high temperature creep is generally slightly smaller than that where a maximum in yicld strength is observed, as shown in Figure. 8. Secondly, although the precipitates in this alloy did not grow significantly when the specimen was aged at $873 \mathrm{~K}$ for a few hundred hours with no applied stress[12], an applied stress at this temperature may promote their growth. This has been observed in the specimen aged for 25 hours at $898 \mathrm{~K}$ and crept for 222 hours at $873 \mathrm{~K}$ and a stress of $720 \mathrm{MNm}^{-2}$. The particle size of $\gamma^{\prime \prime}$ was observed to be $40 \mathrm{~nm}$ in this crept specimen which is larger than that of $32.4 \mathrm{~nm}$ observed in a specimen aged for 25 hours at $998 \mathrm{~K}$ without any applied stress.

\section{Conclusions}

1. The value of effective stress exponent in the creep rate equation suggests that the creep deformation mechanism of Alloy 718 changes from linear or diffusional creep to dislocation power law creep when either temperature or applied stress is increased. The experimental results also suggest that there exists a transition region between the diffusional creep and the dislocation power law creep regions.

2.The grain size influences the creep rate of Alloy 718 differently in the two creep regions, in diffusional creep region $\dot{\varepsilon}_{\mathrm{s}} \alpha \mathrm{d}_{\mathrm{g}}{ }^{-0.19}$ and in dislocation power creep region, $\dot{\varepsilon}_{\mathrm{s}} \alpha \mathrm{d}_{\mathrm{g}}{ }^{0.42}$.

3.The steady state creep rate $\dot{\varepsilon}_{\mathrm{s}}$ of Alloy 718 decreases with increase in the precipitate particle size until a critical particle size is reached. The creep rate then increases with further 
increase in particle sizes. The optimum particle size for minimum high temperature creep rate is slightly smaller than those for maximum room temperature yield strength.

\section{Acknowledgements}

The authors would like to express their thanks to the Natural Science and Engineering Research Council of Canada for their financial support and the International Nickel Company of Canada who supplied material for this study. The authors are also grateful to Dr. Cahoon for his suggestions and discussions, and to Mr. J. Van Dorp for his technical assistance during the experiments of this investigation.

\section{References}

1. A. Lasalmonie and J.L. Strudel, J. Mat. Sci., 21 (1986) 1837

2. D.D. Sherby and P.M. Burke, Prog. Mater. Sci., 13 (1967) 325

3. D. McLean, Rep. Prog. Phys., 29 (1966) 1

4. K. Williams and B. Wilshire, Met. Sci. J., 7 (1973) 176

5. J.D. Parker and B. Wilshire, Met. Sci. J., 12 (1978) 453

6. R. Lagneborg and B. Bergman, Met. Sci. J., 10 (1976) 20

7. A.H. Clauer and B.A. Wilcox, Met. Sci. J., 1 (1967) 86

8. $\quad$ R.W. Lund and W.D. Nix, Acta. Metall., 24 (1976) 469

9. J.C. Gibeling and W.D. Nix, Mat. Sci. Eng., 45 (1980) 123

10. G.S. Ansell and J. Weertman, Trans. Met. Sco. AIME, 251 (1959) 838

11. N.J. Grant in D. Pecker (ed), "The Strengthening of Metals", Reinhold, New York, 1964, p. 163

12. Y. Han, P. Deb and M.C. Chaturvedi, Met. Sci., 16 (1982) 555

13. Y. Han and M.C. Chaturvedi, Mater. Sci. Eng., 85 (1987) 59

14. Y. Han and M.C. Chaturvedi, Mater. Sci. Eng., 89 (1987) 25

15. I.E. Harris, Met. Sci. J., 7 (1973) 1

16. B. Burton, Mat. Sci. Eng., 11 (1973) 337

17. R.J. Coble, J. Appl. Phys., 63 (1963) 1679

18. D. McLean, Metall. Rev., 7 (1962) 481

19. D. McLean and H.F. Hale, "Structural Process in Creep", Iron and Steel Institute, London, 1961, p. 19

20. M.C. Chaturvedi and Y. Han, Met. Sci., 17 (1983) 145

21. C.T. Sims and W.C. Hagel, "The Superalloys", Wiley, New York, 1972, p. 111

22. S. Purushothan and J.K. Tien, Acta Metall., 26 (1978) 1007

23. M.F. Ashby in A. Kelley and R.B. Nicholson (eds), "Strengthening Methods in Crystals", Applied Science, London, 1972, p. 137 